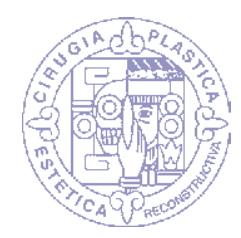

\title{
La presentación de trabajos libres en el Congreso Anual Internacional de la Asociación Mexicana de Cirugía Plástica, Estética y Reconstructiva
}

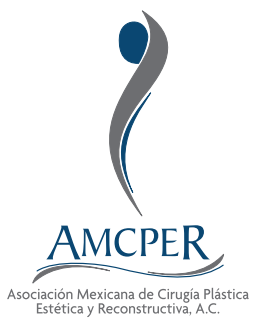

The presentation of free papers in the Annual International Congress of the Mexican Association of Plastic, Aesthetic and Reconstructive Surgery

\section{Dr. Antonio Espinosa de los Monteros*}

$\mathrm{L}$ a presentación de trabajos libres es un componente primordial de los congresos, ya que permite que los miembros de la comunidad científica en cuestión puedan mostrar los resultados de su trabajo, al tiempo que otros miembros conocen conceptos nuevos a partir de ellos. A lo largo de la historia, han existido numerosos artículos publicados que representan documentos importantes en la transmisión de conceptos científicos, en los que se establece que esa información había sido presentada con anterioridad en la forma de un trabajo libre en algún congreso. En numerosas ocasiones, los trabajos libres son el medio en el que se da a conocer por vez primera un concepto, técnica o resultado.

Durante los últimos dos Congresos Anuales Internacionales de la AMCPER se presentó un total de 156 trabajos libres, de los cuales 104 fueron en cartel, 37 se presentaron en forma oral y 15 se presentaron bajo el formato de técnica quirúrgica innovadora. En cuanto a los temas abordados, el que tuvo mayor proporción fue el de procedimientos faciales con $26 \%$, seguido por cirugía del contorno corporal en $15 \%$, cirugía de mano en $12 \%$, cirugía de miembros inferiores en $8 \%$, quemaduras en $8 \%$, rinoplastia en $8 \%$, reconstrucción del tronco en $8 \%$, cirugía de brazos en $7 \%$, cirugía glútea en $3 \%$, cirugía craneana en $3 \%$ y cirugía de genitales en $2 \%$.
El Comité del Concurso de Trabajos Libres «Dr. Mario González Ulloa» estuvo formado por siete cirujanos plásticos miembros de la AMCPER. Los trabajos fueron calificados en forma ciega; es decir, sin conocer los nombres y lugares de adscripción de los autores, siguiendo una serie de criterios, dentro de los cuales, los que mostraron mayor impacto tuvieron que ver con que el trabajo estuviera completo, con el cumplimiento de su objetivo, la utilidad de los resultados obtenidos y la presencia de un análisis científico.

Sin excepción, todos los trabajos libres de los congresos anuales internacionales de la AMCPER de 2017 y 2018 se presentaron en forma excelsa, reflejando la capacidad de los cirujanos plásticos mexicanos para generar y transmitir conceptos en el campo de la Cirugía Plástica, Estética y Reconstructiva. En el futuro, muchos de estos trabajos se verán plasmados en publicaciones científicas, de forma que la información pueda compartirse a lo largo de las generaciones venideras.

Correspondencia:

Dr. Antonio Espinosa de los Monteros

Vasco de Quiroga Núm. 15,

Col. Sección 16,

Alcaldía Tlalpan, 14000,

Ciudad de México, México.

Tel. 54870900, extensión 2133.

E-mail: aedlms@hotmail.com 